\title{
PUBLIC PERCEPTION ON DISASTER MANAGEMENT USING VOLUNTEERED GEOGRAPHIC INFORMATION (VGI): CASE OF UAE
}

\author{
M. M. Yagoub \\ Department of Geography and Urban Planning \\ Faculty of Humanities and Social Sciences \\ United Arab Emirates University, P. O. Box 17771, Al Ain \\ E-mail:myagoub@uaeu.ac.ae \\ :myagoub@hotmail.com \\ URL : http://faculty.uaeu.ac.ae/myagoub
}

KEYWORDS: VGI, UAE, public perception, disaster management.

\begin{abstract}
:
The number of smart phones that are supported by location facility like Global Positioning System (GPS), Camera and connected to the internet has increased sharply in UAE during the last five years. This increase offers a chance to capitalize on using these devices as resources for data collection, therefore reducing cost. In many cases specific events may happen in areas or at time where there may be no governmental departments to collect such unrepeated events. The current research will showcase various studies that had been conducted on Volunteered Geographic Information (VGI) debating various aspects such as accuracy, legal issues, and privacy. This research will also integrate Geographic Information System (GIS), VGI, social media tools, data mining, and mobile technology to design a conceptual framework for promoting public participation in UAE. The data gathered through survey will be helpful in correlating various aspects of VGI. Since there are diverse views about these aspects, policy makers are left undecided in many countries about how to deal with VGI. The assessment of the UAE case will contribute to the age-long debate by examining the willingness of the public to participate. The result will show the public perception to be as sensors for data collection. Additionally, the potential of citizen involvement in the risk and disaster management process by providing voluntary data collected for VGI applications will also be explored in the paper.
\end{abstract}

\section{INTRODUCTION}

The recent advancement in GIS and rapidly emerging phenomenon in which contribution is mainly by people, either individually or collectively for the use of information to many others is now termed as Volunteered geographic information (VGI). Individuals as moving sensors for data collection had been discussed widely under Volunteer Geographic Information (VGI) (Goodchild, 2007).

The term VGI has been used in both public and private contexts for sharing of variety of information in a very broad range of circumstances. For example, governments can use citizens to be a part of data collection which otherwise is difficult to collect and verify. VGI requires providers which will disseminate the information in geographical context. Users might be asked to express the place names which can be local or vernacular; information about permanent or transient geographical features; disaster or emergency condition information; natural phenomenon mapping; community mapping, such as user generated pothole maps; or other social or political phenomenon maps. For example Al Ain Municipality in UAE invited the public to collect sound data using their smart phones applications.

For disaster response, information can be collected from VGI providing a reliable source (Goodchild and Glennon, 2010). In many cases, open source cartographic products based on VGI, such as Open Street Map (OSM) are used as an alternative to various products such as maps or guidebooks that are costly enough to produce and are available in the market at a price. VGI also have an added advantage for dispersing the contemporary information to permit decentralization of the information generation process. Some VGI initiatives leverage opportunities to gather data that is otherwise extremely difficult and costly to collect.

In recent years, there has been an eruption of interest for using internet as a primary source for creation, assembling and disseminate geographic information provided by individuals voluntarily. They need better tools and information to support decisions about how to inform wisely and cost-effectively in risk-reduction measures and updating the data to the concerned authority (Dinitz and Taketa, 2013). The emerging websites like Wikimapia and data mapping platform like OSM are allowing citizens to put all the pieces of geographic information on the correct places, while Google Earth and other internet giants are encouraging volunteers to develop interesting applications using their own data. One of the most convincing examples of VGI is Wikimapia, which formed a base for creation of Wikipedia Encyclopedia. Anyone having an internet connection is now able to provide description on any area of earth's surface, including links to other sources. Anyone can edit entries, and then volunteer reviewers used to monitor the results, checking for accuracy and significance.

Any information is considered personal if it is about an identifiable individual. For example, a geo-referenced photograph which is having a certain recognizable individual, will likely to be considered as personal information of those individuals (Scassa, 2010). It is always believable that any type of information linked with geographic coordinates may reveal personal information. VGI site operators are potentially liable for providing the information needed for different purposes (Chandler and Levitt, 2011). The vast information comes from variety of contributors should be verified through different sources too. Government acts as a prime source for providing all types of data. When requested for information, it is typically stripped of personal information. However, this technology can be powerful information for re-identification and users of this information should take care of their activities which should not 
result in disclosure of personal information without consent (El Emam et al. 2009; Sweeney, 2002). Elwood and Leszczynski (2011) focused on the nature of representation, arguing that geotagged photographs and pseudo-realistic panoramas of public spaces introduce much more immediate, embodied, less abstract modes of identification than in prior digital representations of spatial information, with implications for social contracts around privacy.

Many exciting developments in data mining and knowledge discovery have been reported elsewhere (Miller and Han, 2009) but robust methodologies for productive VGI applications should not be confined to analysis alone. Instead, the current tide seems to place new emphasis on synthesis. Services such as Microsoft's Photosynth, IBM's ManyEyes, HistoryFlow, and TouchGraph provide examples of services for synthesizing data in diverse media.

The overall challenges for effective GIS interfaces with the use of new techniques to support crisis management in three forms: immediacy, relevance and sharing (Guoray et al., 2006). Compared to conventionally produced forms of geographic information, VGI is different along several axes: the content of the information, the technologies for acquiring it, issues surrounding its quality (Alexis et al., 2013), the methods and techniques for working with it, and the social processes that mediate its creation and impacts (Coleman et al., 2009; Elwood, 2008; Scassa, 2013).

With the increase in number of studies aimed to explore the technical, socio-economic and socio-political opportunities of these new volunteer activities for spatial data collection (Genovese and Roche, 2010), we are now entering in a new era of social involvement. This gives concern to a wide range of questions and issues connected to it like: What acts as an inspiration for the people to voluntarily contribute spatial data (Coleman et al., 2009)?, How accurate are the results (Alexis et al., 2013)? What are the criteria followed for authenticating the reliability of contributors (Bégin et al., 2014)? What methods are used to confirm that information? What kind of new parameters should be followed and developed to assess the quality of VGI? Is the data updated by public pose a threat or concern to an individual's privacy or even national security? What if criminals use this data for illegal activities or put in false information in the data model?

\section{VOLUNTEERED GEOGRAPHIC INFORMATION (VGI) IN UAE}

Volunteer geographic information is a great success in UAE and provides a vast support to the government also and this all is due to increase in smart phones and mobile devices users. Now, the devices are well equipped with GPS, camera and low cost internet, helping them to participate in VGI. UAE is a key player in the middle east which is spreading smart education to its students and thus increasing the public participation in social responsibility. There are many organizations and departments either governmental or non-governmental like Sanid (http://www.sanid.ae) and Takatof (http://www.takatof.ae) which are working to filter the data coming through local public and make it more useful for others as well as extracting information out of it in UAE making it more cost efficient. One such application is "Abu Dhabi City Guard" that is provided by
Abu Dhabi Systems \& Information Centre (ADSIC) (http://www.abudhabi.ae/cityguard).

ADSIC urged Abu Dhabi residents to get involved in reporting city incidents using the new CityGuard mobile application. To maintain the city's appeal and further strengthen its international image, safety standards and quality of services for residents and travelers. To that end, the new application aims to encourage both residents and tourists to join the government's efforts in resolving problems quickly and effectively. A minute or so of finger tapping is all it takes to document an issue by taking a photo or recording a video or audio and reporting it directly to the Abu Dhabi Contact Centre.

Other smart applications in UAE which encompass VGI are Dubai Police ensuring residents to report crime happening while in Abu Dhabi Police app, an emergency button has been given instantly sends a text or place an emergency call. Federal Electricity and Water Authority (FEWA) mobile is also an intuitive application that provides FEWA's customers with real time information of any leakage or fault and guides the nearest technician to solve the issue. Fujairah Natural Resources Corporation developed in 2014 a GPS supported application "Labaik Fujairah" that offers the public easy access to the Authority's resources and a chance to report any environmental issues (Al Bayan Newspaper, 2015). In addition to that there are some applications that serve addressing systems such as Onwani by Abu Dhabi Municipality and Makani by Dubai Municipality.

\section{OBJECTIVE}

The main objective of this study is to understand the perception of public for VGI and to identify how information from volunteers is of great value in achieving help for any of the cause like disaster, social or any other. Many studies carried out earlier in different parts of the world (Hodgsen et al., 2014) were taken into account and rightly chosen to extract meaningful information from the data achieved publicly for UAE.

\section{METHODOLOGY}

Taking initiatives in public participation through VGI is not easy and usually requires consideration of many factors such as operational requirements and risks (e.g., scale, scope, timeline, budget, regulation, and target problem), participant selection (e.g., number, target group, sampling method, diversity and ethnicity), information provision and diffusion (e.g., distribution, channel, content, and feedback), consultation over specified options, and problem-based deliberation (Lowndes et al., 2001). The formulation of research questions plays an important role during the planning stage because they will be used as guidelines to define the activities and processes employed in the execution (Bégin et al., 2014). Compared to face-to-face meetings or physical forms, technology-based interactions are able to achieve near-real time communication and encourage people to honestly and freely pass on the information through a virtual medium.

VGI adopts a bottom-up approach that engages a large number of citizens and shifts the role of users from mere "data consumers to active participants and providers" of usergenerated content. The aforementioned phrase can be verified by the article (Foody et al., 2014) which outlines the potential of citizen science in mapping activities. There are different means of evaluating and interpreting all the studies available in the 
literature about research questions, area, or phenomenon of interest for VGI. Accordingly, there are three major steps which comprise this volunteered survey: planning, organizing and analysis. In the planning phase, literature reviews and questionnaire development was carried out which further make the way to meaningful organization of the questions. The third phase deals with the analysis and how to extract meaningful answers from the data.

As many researchers collected data through Web based as well as offline questionnaires to receive information about a specific topic (Fohringer et al., 2013). Around 17 questions were prepared for this research keeping in mind the previous researches procedures. These cover nearly many aspects related to VGI as well as new technologies that is continuously changing the world. The questions are interrelated with each other, providing a complete vision on how people are reacting at the time of needs and how authority is using the data for gaining information. This can leverage local intelligence to benefit local government, state agencies in improving decision quality, reducing process time, promoting cost effectiveness, maintaining transparency and legitimacy, and ultimately contributing to the development of a civil society (Creighton, 2005). In addition to the need for robust wireless transfer of the retrieved data, privacy is also critical in this scenario, and hence encryption techniques are necessary.

With regard to the use of VGI for different phases, the important questions were identified to concentrate more on use of smart phones and its applications for the awareness purposes and to understand people response on chip based tracking devices. This will entail them to carry out activities for managing disasters related to fire, floods, earthquake etc (Flanagin and Metzger, 2008). Some other questions were also taken into consideration to appreciate the spread of information within the community and outside in case of any disaster happening. The prevailing media for sharing VGI can be through various sources like Twitter, Facebook, YouTube or other VGI platforms like Ushaidi (http://www.ushahidi.com/), Elva (http://www.myelva.com/), Open Street Map, and Wikimapia (Schelhorn et al., 2014). The first few questions set, asked for the basic demographic information of the participants. The questions included gender, participation in geographic data collection voluntarily, internet usage on mobile and use of GPS tracker in it. The other question set comprises of main component of the study and is included in here to help participants understand the need of this data.

After reading each scenario, participants were asked to complete a functional task related to their own situation (e.g., using GPS tracking facility) using mobile phones and then answer a few survey questions about the functionality and usage. These questions reflected different evaluation criteria and directed the subjects to compare the experience attained by them in the past with the use of latest technology now.

The basic idea behind this study is to know the awareness among the people in case of some hazard situations and how they can collect useful information using tracking chips or GPS. Almost $75 \%$ of the people in UAE are connected with internet on their mobile phones and can harness geospatial technology to benefit non-expert users or communities. This includes the participatory frameworks which leverage public citizens' local knowledge and observations with an associated geospatial footprint such as an address (Schade et al., 2011).

Although involving members of the public in risk decisionmaking is a key concept of risk governance, efforts to date shows a mixed success (Driedger et al., 2009). With the increasing influence of VGI, information from virtual communities and social media networks becomes an important part of local intelligence and contributes to the aggregation of web maps and user-generated content. In this way, users can easily access the information to discover any catastrophic events and activities through social media posts. Evaluation of the effectiveness of public participation can be difficult at some time. The major factors in evaluating the effectiveness of data and providing it to right person are effectiveness, which highlights the openness of processes and information, simplicity and clarity. Comprehensibility, which examines whether laymen understands the seriousness of the information and produces it further. For this, another factor called empowerment comes into mind which examines whether an activity or system educates the public and enhances participant trust, and evaluates the impact of each party of the decision.

\section{ANALYSIS}

Recently the advancement of Internet technology and the proliferation of Web 2.0 bring new behaviors to a geographically-enabled information society and infuse public participation with new energy. Benefits of involving public participation include integrating citizens' views to support better decision making, improving current state-of-art services, promoting sense of ownership, and creating a knowledge base to inform and educate the public (Lowndes et al., 2001). Based on a combination and transformation of the evaluation study outlined previously, a survey questionnaire was designed to collect public user feedback. A VGI survey conducted in university among the students, respondents indicated and revealed many ideas related to public participation in GIS. Of particular interest in this research survey, we listed 17 questions indicative of the built up environment for getting the vision of what people are thinking and responding in case of an emergency. Perhaps the most important aspect in this survey was to educate people and to make them understand about the use of their voluntary participation for some great cause and to be prepared for any worse that can happen anytime. The framework for the questionnaire includes empowerment as well as other criteria like accessibility which examines the openness of processes and information in its clarified form.

Since GIS and VGI are two of the major technologies used in this study, previous GIS experience and social media usage were regarded as factors that could impact user evaluation of this information system. While safety is the main motivation for wireless position location, other promising applications include accident reporting, navigational services, automated billing, fraud detection, roadside assistance, and cargo tracking. Position location systems in mobiles provide greater crimefighting capabilities for law enforcement personnel, and new methods for tracking people and parcels (Rappapon et al., 1996).

Smart phones are the vital source of communication these days and so do our study is focusing more on it. Research efforts on information retrieval and spreading by mobile devices have been made with some aspects of utilizing context information including location, personal profiles, time of day. Gravano et al. (2003) study the problem of location based search and passing the information further on to the authority.

The study receives initially 509 public user responses through hard copy questionnaire out of which 72 (66\%) were females. This high female percentage is due to the high number of female students in UAE University (almost 70\%). Additional 140 questionnaires were distributed to male faculty and staff in order to provide a balance in gender ratio. Out of the total 648 surveys $52 \%$ were female and $48 \%$ were male. The survey 
conducted in UAE University shows us that most of the people do not start the GPS tracking in their mobiles and the probable reason for that came out to be the excess draining of battery. $80 \%$ of the people confessed that they start the tracking only on demand or in case of emergency. This is diverting their understanding about the usefulness of trackers in the mobile and so the time has come when a new alternative should be introduced which will provide them more comfort and simultaneously do its work also so that the person can be tracked in time of emergencies.

There are some methods adopted worldwide for locating lost persons in hazardous situations. Since it may be the case a person does not put the tracker ON in his/her smart phone every time. A personal identification card is been provided to every person which has pre-assigned unique identifying indicia thereon having all of his personal details and an emergency contact number. These have magnetic strips placed in the card and is generally used for transaction processing and access control. The other method is a radio frequency identifier, which transmits a radio frequency and is read by a receiver. The power used for this is generated internally and the radio frequency chip can be installed inside the identity card of the person. A similar system for tracking the students have been adopted in MIT which is working fine and the concern about privacy and safety have prevail over by educating them about the policy for that that (Priya et al., 2004).

In UAE, as per the survey conducted mostly all persons agree on the tracking chip been installed in their identity cards but $58 \%$ were concerned about their privacy and were not very comfortable with it. The solution for this concern is to educate them about the usefulness of this chip and the policy adopted for the privacy too.

Since the formation of UAE, government had taken many steps to spread the education among people of this country and due to those efforts a large population is now educated and this improves their understanding on how to react whenever they see an unwanted event happening. As per the survey shows, people used to call the concerned authority instead of police at the time of any disastrous event. This is due to their increased knowledge about various departments to be reported for concerned incident. But, the concerned part is that they are still following the traditional way to give the location of the event. The survey highlights that around $25 \%$ of the population who had seen those unusual events have called the authority but gave them descriptive location. A large majority of respondents, $51 \%$, called police department seeing an unusual event while $28 \%$ reported the incident to concerned department. Around $82 \%$ of the participants were never involved in geographical data collection voluntarily.

It is now time to educate them about the accuracy of GPS coordinates over the traditional way of giving location as around $75 \%$ citizens still rely on giving descriptive location only. This will reduce the time required for the police and the emergency personnel to reach the location with more precision and in less time. Around $70 \%$ of the people do not know about the positional accuracy of their GPS device in phone. This may be a reason of choosing the descriptive location over GPS coordinates by them.

Many online applications are working all over the world to share the information online within the local community or outside to report any event (Hedley, 2012). MindMixer is perhaps the most widely-used and most well-known public participation tool for local community initiatives in the US at this time. Founded on the idea that public participation should be facilitated in a more effective and efficient manner than it has been traditionally, MindMixer encourages citizens to give feedback, generate and share ideas, and feel empowered by and connected to their communities. Other service applications working in different countries are Urban Interactive Studio, Delib, Crowdbrite, Change By Us, Ideascale. These platforms allow participants to share their ideas on city policy and development-related topics; give feedback; and comment on or "second" other's ideas, thus promoting the most popular ideas to the top of the list.

For UAE, such platform is provided by many governmental departments such as ADSIC (Abu Dhabi City Guard). This is a mobile application offered for free to all Abu Dhabi residents, be it UAE nationals, working expatriates, or visitors to the Emirate. City Guard allows the public to report incidents and submit complaints related to the Abu Dhabi Emirate directly to the government. Unfortunately, a few people know about it as been depicted in our survey $(43 \%)$ and that is why more of the awareness need to be spread so that people can use it effectively in case of emergencies.

Ever since humans have evolved, there was always a need to share the views and provide a method to help the others for better understanding. This gave birth to the internet and social media which include phenomena called social networks such as LinkedIn and Facebook, user-generated content like Flickr and Youtube, and crowdsourced information such as Wikipedia and Open Street Map. Part of this development is the creating of mashups or combinations of digital maps and many types of location-based information. The main question derived directly from the research objectives was: how are geographical and other information regarding spatial plans shared through social media, and does this enhance participation in the spatial planning process? The answer for this may be by evaluating both the geographical and non-geographical components of the information shared, and the people sharing information. The use of mobile technology having these applications installed in it will provide an easy platform for the people on time of need to share the critical information that they had seen. Almost $87 \%$ of the respondents for this survey in UAE have these applications installed in their phones and will provide them one day, the opportunity to participate in VGI.

\section{CONCLUSIONS}

VGI represents an unprecedented shift in the content, characteristics, and modes of geographic information creation, sharing, dissemination, and use. Despite concerns over the quality and trustworthiness of VGI, preliminary assessment seems to indicate that VGI could serve as a potential data source to address research questions across geography.

The potential of up to 10 million humans to monitor the state of the environment, to validate global models with local knowledge, and to provide information that only humans can capture is vast and has yet to be fully exploited in UAE. Following this line of thought and considering the fact that casual events that trigger crises cannot be always be detected (and/or followed) by humans, VGI should complement other sources for Earth Observation and as a result, new technology advancement is taken into consideration including sensors, chips. This study shows that in the context of outdoor adventure, VGI may play the greatest role in information gathering prior to any disastrous activity. It can also outrun the technology of delivering real time location based information through GPS enabled mobile devices. During the event itself internal information in the form of personal experience plays a key role in shaping the users decisions and actions.

Furthermore, development of the information and communication technology like VGI could be used as an input 
for crisis management in UAE and later to refine its output results. The advantage is to provide high scale value added information at low cost. This also shows the awareness among the people of UAE for the internet and how they can use the resources effectively at the time of emergency.

In addition, it remains to be examined how different phenomena impact the content of different VGI platforms and the attention of crisis by (social) media and by VGI platforms needs to be analyzed correctly. We expect that if we want to trace a crisis event throughout its lifecycle, i.e., from onset to damage assessment, to reconstruction, we cannot rely on a single platform. Developing means to access multiple platforms in a harmonized manner is a necessary building block that has to be provided as an initial step, but it will be sufficient for implementing VGI.

This study established a relationship between the use of VGI in disaster management and the role of common people using it which came out to be low but increasing gradually, with a significant growth in the number of incidences reported over the last few years in UAE. The main concern still is about the privacy matters which halt the public participation level and the long battery life of the mobile devices which prevents the participants to use it regularly.

\section{REFERENCES}

Al Bayan Newspaper, 2015. Fujairah Natural Resources Corporation developed in 2014 "Labaik Fujairah" Application. 10 January, 2015, No. 12624, p.07.

Alexis, C., Linda S., Steffen F., Marijn, V. V., Christoph, P., Giles F., 2013. Using control data to determine the reliability of volunteered geographic information about land cover. International Journal of Applied Earth Observation and Geoinformation, Vol. 23,pp.37-48.

Bégin, D., Devillers, R. and Roche, S., 2014. Assessing volunteered geographic information (VGI) quality based on contributors mapping behaviors. 8th International Symposium on Spatial Data Quality. 30 May - 1 June 2013. Hong Kong.

Chandler, J.A. and Levitt, K., 2011. Spatial data quality: The duty to warn users of risks associated with using spatial data. Alberta Law Review, Vol. 49, No.1, pp.79-106.

Coleman, D.J., Georgiadou, Y. and Labonte, J., 2009.Volunteered geographic information: The nature and motivation of producers. International Journal of Spatial Data Infrastructures Research, Vol.4, pp.332-358.

Comber, A., See, L., Fritz, S., Van Der Velde M, Perger, C., Foody, G., 2013. Using control data to determine the reliability of volunteered geographic information about land cover. International Journal of Applied Earth Observation and Geoinformation, Vol.23, pp.37-48.

Creighton, J.L., 2005.The Public Participation Handbook: Making Better Decisions through Citizen Involvement. San Francisco, CA: Jossey-Bass.

Cyclopath, 2015. User agreement. http://cyclopath.org/wiki/User_Agreement (Accessed on 16 January 2015).

Dinitz, L.B. and Taketa, R.A., 2013. Applying the Land Use Portfolio Model with Hazus to analyse risk from natural hazard events. International Journal of Risk Assessment and Management, Vol. 17, No. 1, pp.69-88.

Driedger, S.M., Cynthia, G.J., Turtiak, M., 2009. Public participation and risk governance: opportunities and barriers. International Journal of Risk Assessment and Management, Vol.13, pp. 260-275.

El Emam, K., Brown, A. and Malik, P.A., 2009. Evaluating predictors of geographic area population size cut-offs to manage re-identification risk. Journal of the American Medical Informatics Association, Vol.16, No.2, pp.256266.

Elwood, S., 2008. Volunteered geographic information: Key questions, concepts and methods to guide emerging research and practice. GeoJournal, Vol.72, pp.133135.

Elwood, S. and Leszczynski, A., 2011. Privacy reconsidered: New representations, data practices, and the geoweb. Geoforum, Vol.42, No.1, pp.6-15.

Flanagin, A.J. and Metzger, M.J. ,2008. The credibility of volunteered geographic information. GeoJournal, Vol.72, Nos.3-4, pp.137-148.

Fohringer, D. D. J., Poser, K., and Lucas, C. 2013. Volunteered Geographic Information for Disaster Management. Citizen E-Participation in Urban Governance: Crowdsourcing and Collaborative Creativity: Crowdsourcing and Collaborative Creativity, 98.

Foody, G., Fritz, S., See, L., Kerle, N., Hart, G., and Fonte, C. 2014. Enhancing the role of Citizen Sensors in Mapping: COST Action TD1202.

Genovese, E., \& Roche, S., 2010. Potential of VGI as a resource for SDIs in the North/South context. Geomatica, 64(4), 439-450.

Goodchild, M.F. , 2007. Citizens as sensors: The world of volunteered geography. GeoJournal, Vol. 69, No. 4, pp.211-221.

Goodchild, M.F. and Glennon, J.A., 2010. Crowd sourcing geographic information for disaster response: A research frontier. International Journal of Digital Earth, Vol. 3, No.3, pp.231-241.

Gravano, L., Hatzivassiloglou, V., Lichtenstein, R., 2003. Categorizing web queries according to geographical locality. In: 12th ACM Conference on Information and Knowledge Management (CIKM 2003), New Orleans, Louisiana, USA.

Guoray, C., Sharma, R., MacEachren, A. M., Brewer, I. , 2006. Human-GIS interaction issues in crisis response. International Journal of Risk Assessment and Management, Vol.6, No.4/5/6, pp.388 - 407

Hedley, N., 2012. Capturing communities perceptions of risk through the eyes of their citizens: using mobile VGI networks to map tsunami risk awareness. Proceedings of the 9th International ISCRAM Conference, April 2012, Vancouver, Canada.

Hodgson, M.E., Battersby, S.E., Davis, B.A., Liu, S. and Sulewski, L. , 2014. Geospatial Data Collection/Use in Disaster Response: A United States Nationwide Survey of State Agencies. In Cartography from Pole to Pole (pp. 407-419). Springer Berlin Heidelberg.

Horita, F.E.A., Lívia, C.D., Luiz, F.F.G.A., Zipf, A. and J.P. de Albuquerque, 2013.The use of Volunteered Geographic Information and Crowd sourcing in Disaster Management: a Systematic Literature Review. Proceedings of the Nineteenth Americas Conference on Information Systems, Chicago, Illinois, August 15-17, 2013.

Lowndes, V., Pratchett, L. and Stoker, G., 2001.Trends in public participation: part 1 - local government perspectives. Public Administration, Vol.79, No.1, pp. 205-222. 
Miller, H.J. and Han, J., 2009. Geographic data mining and knowledge discovery. Boca Raton, FL: CRC Press.

Priya A., Neha B., Chaitra C., Al Dahya and Zamfirescu J.D., 2004. The MIT card system: Analysis and Recommendations. Retrieved from http://groups.csail.mit.edu/mac/classes/6.805/studentpapers/fall04-papers/mit id/

Rappapon, T.S., Reed, J.H. and Woemer, B.D., 1996. Position location using wireless communications on highways of the future. IEEE Communication Magazine, Vol.34, No.10, pp 33-41.

Scassa, T., 2010. Geographic information as personal information. Oxford University Commonwealth Law Journal, Vol. 10, pp.185-214.

Scassa, T. , 2013. Legal issues with volunteered geographic information. The Canadian Geographer, Vol. 57,
No.1,
pp.1-10.
DOI:
$10.1111 / \mathrm{j} .1541-$

0064.2012.00444.x

Schade, S., Diaz, L., Ostermann, F., Spinsanti, L., Luraschi, G., Cox, S., Nuñez, M. and Longueville, B., 2011. Citizen based sensing of crisis events: sensor web enablement for volunteered geographic information. Applied Geomatics, pp.1-16.

Schelhorn, S.J., Benjamin, H., Richard, L., Alexander, Z. and J.P. de Albuquerque, 2014. Identifying Elements at Risk from Open Street Map: The Case of Flooding. Proceedings of the 11th International ISCRAM Conference. May 2014. University Park, Pennsylvania, USA.

Sweeney, L., 2002. K-anonymity: A model for protecting privacy. International Journal on Uncertainty, Fuzziness and Knowledge-Based Systems, Vol.10, No.5, pp. 557-570. 